\title{
Capacidades individuais da burocracia pública do agronegócio brasileiro
}

\section{Gustavo Leonardo Simão ${ }^{1}$}

\section{Suely de Fátima Ramos Silveira ${ }^{2}$}

1 Universidade Federal do Espírito Santo / Departamento de Administração, Vitória / ES - Brasil

2 Universidade Federal de Viçosa / Departamento de Administração e Contabilidade, Viçosa / MG - Brasil

Este artigo aborda a capacidade individual da burocracia pública federal, no âmbito dos servidores ocupantes de posições de Direção e Assessoramento Superior (DAS), para a resolução dos problemas no contexto do agronegócio brasileiro. Os dados foram obtidos por meio do Sistema Integrado de Administração de Pessoal (SIAPE). Foram delimitadas três proxies como bases formativas de um construto de análise no intuito de representar a capacidade individual da burocracia vinculada ao Ministério da Agricultura, Pecuária e Abastecimento (MAPA): política, operacional e analítica. Essas proxies foram analisadas sob uma abordagem quantitativo-descritiva. Inicialmente, verificou-se o nível de rotatividade dos burocratas no período de 1999 a 2012. Posteriormente, por meio do teste de amostras independentes Mann-Whitney U, foram comparados dados de 1998 e 2018, como forma de verificar modificações nas competências operacionais e analíticas, representadas pela capacidade de liderança e habilidade de processar informações, respectivamente. O conjunto de fatos resultantes evidenciam certo conservadorismo da capacidade individual da burocracia do MAPA, uma vez que se observam a não modificação de ocupantes de cargos mais elevados na condição de efetivos, com destaque para aqueles na posição de ativos permanentes, e a não evolução do nível de instrução formal.

Palavras-chave: burocratas; serviço público; competências.

\section{Capacidades individuales de la burocracia pública del agronegocio brasileño}

Este artículo aborda la capacidad individual del gobierno para resolver problemas en el contexto de los agronegocios brasileños, específicamente al nivel de la burocracia en el estrato de Gestión Superior y Asesoría (DAS). Los datos se obtuvieron a través de la base de datos del Sistema Integrado de Administración de Personal (SIAPE). Tres proxies se definieron como bases formativas para el análisis a fin de reflejar la capacidad individual de la burocracia vinculada al Ministerio de Agricultura, Ganadería y Abastecimiento (MAPA) en las competencias política, operativa y analítica. Estas aproximaciones se analizaron utilizando un enfoque cuantitativo-descriptivo. Inicialmente, se verificó el nivel de rotación de los burócratas, de 1999 a 2012. Posteriormente, utilizando la prueba de muestras independientes U de Mann-Whitney, se compararon los datos de 1998 y 2018 como una forma de verificar los cambios en las competencias operativas y analíticas, representadas por la capacidad de liderazgo y la habilidad de procesar información, respectivamente. El conjunto de hechos resultantes muestra un cierto conservadurismo de la capacidad individual de la burocracia del MAPA, dada la no modificación de ocupantes de cargos superiores en la condición de personal permanente, con énfasis en los de carrera en el propio órgano, y la no evolución del nivel de educación formal.

Palabras clave: burócratas; servicio público; competencias.

\section{Individual capabilities of the Brazilian agribusiness public bureaucracy}

This article analyzes the individual capabilities of government employees working in Superior Management and Advisory (SMA) positions in the Brazilian federal bureaucracy regarding the solution of problems in the agribusiness sector. The data were obtained from the Integrated Personnel Administration System (IPAS). Three proxies were defined to build an analytical construct to reflect the individual capabilities of the Ministry of Agriculture, Livestock, and Supply's (MALS) personnel: political, operational, and analytical competencies. The proxies were analyzed using a quantitative-descriptive approach. The study observed the bureaucrat's turnover from 1999 to 2012. Subsequently, using the Mann-Whitney U test for independent samples, data from 1998 and 2018 were compared to verify changes in operational and analytical competencies, represented by the leadership capacity and ability to process information, respectively. The results showed that the individual capability of MALS's personnel remained unchanged, indicated by the permanence of tenured employees in high-level positions and the maintenance of the level of formal education, which did not evolve over time.

Keywords: bureaucrats; public service; competence. 


\section{AGRADECIMENTOS}

Os autores agradecem aos pesquisadores do Instituto de Pesquisa Econômica Aplicada (Ipea) pela cessão dos microdados utilizados neste artigo e à Coordenação de Aperfeiçoamento de Pessoal de Nível Superior (CAPES) pelo financiamento que tornou possível a realização da pesquisa (Bolsa PNPD - Processo n. 88887.314326/2019-00).

\section{INTRODUÇÃO}

A elaboração de políticas públicas eficazes, eficientes e equitativas pelos atores governamentais é essencial na gestão pública, dada a limitação dos recursos financeiros em virtude das crescentes e distintas demandas sociais (Fischer, Miller \& Sidney, 2007; Kraft \& Furlong, 2007; Mukherjee \& Bali, 2019; Souza, 2017). Assim, diversas ações têm sido empreendidas ao longo do tempo, seja em relação à reestruturação das formas de governo, com as reformas administrativas - sob as perspectivas ideológico-comportamentais dos agentes políticos -, seja por meio da incorporação progressiva de inovações ${ }^{1}$ no escopo da gestão pública (Gow, 2012; Steingerg, 2014).

No entanto, a capacidade individual da burocracia pública, entendida como um fator-chave para o sucesso das intervenções governamentais (Baekgaard, Mortensen \& Seeberg, 2018; Wu, Howlett \& Ramesh, 2018), tem tido menor atenção. Pires (2012) e Olsen (2006) ressaltam, que, a despeito de alguns estudos focalizarem a análise do papel exercido pela burocracia na estrutura governamental, ainda há uma omissão na focalização do perfil desses atores e de suas implicações no que concerne à assertividade das ações empreendidas, ou seja, a capacidade governamental de aprimorar suas condições de entrega de melhores serviços aos cidadãos. Assim, essa capacidade está relacionada à solução de problemas públicos e as diversas formas (características) como as instituições são desenhadas e estruturadas, o que reflete em como elas funcionam.

Ademais, no Brasil, especificamente, com a promulgação da Constituição de 1988, houve uma progressiva ampliação do aparato burocrático, uma vez que as atribuições governamentais na entrega de serviços, notavelmente nas áreas sociais, foram majoradas (Souza, 2001,2014). Têm sido realizadas pesquisas para a compreensão do perfil da burocracia no nível geral do governo federal brasileiro, ou seja, de maneira agregada, como se verifica em Lopez, M. Bugarin e K. Bugarin (2014) e também em Pires, Lotta e Oliveira (2018); bem como outras dedicadas a setores considerados importantes, como em Paula, Palotti, Cavalcante e Alves (2017) sobre a área de transportes e energia. Contudo um setor econômico em específico tem sido preterido nesses estudos: o agronegócio.

Muito embora o agronegócio possa ser considerado um setor estratégico de primeira ordem na conjuntura da administração pública brasileira, principalmente pelo equilíbrio que ele tem propiciado a déficits de outras áreas (Moreira, Kureski \& Pereira-Veiga, 2016), são incipientes os estudos destinados ao entendimento da burocracia nesse campo. Ao congregar uma estrutura organizacional extensa, com políticas públicas voltadas a distintas agendas e públicos-alvo distintos, a eficácia ou não das intervenções governamentais no setor rural brasileiro depende diretamente da capacidade do corpo técnico do Ministério da Agricultura, Pecuária e Abastecimento (MAPA).

\footnotetext{
${ }^{1}$ Vries, Bekkers e Tummers (2016), em análise sistemática das pesquisas relacionadas ao estudo da inovação nas organizações públicas, indicaram que um dos objetivos almejados é a ampliação da eficiência e eficácia.
} 
No trabalho de Simão et al. (2017), por exemplo, constatou-se que uma redução no interesse de produtores rurais de regiões pobres em participar do Programa de Aquisição de Alimentos (PAA) estava atrelada a modificações constantes na forma de prestação de contas, na descontinuidade do programa $^{2}$ e no atraso na liberação dos pagamentos dos alimentos por parte da Companhia Nacional de Abastecimento (Conab) ${ }^{3}$. Já Igari e Pivello (2011) salientam que, à época da criação do Código Florestal, especificamente no ano de 1965, o então ministro do MAPA creditou a um grupo de servidores a construção do desenho do anteprojeto por acreditar obter um resultado mais aderente à realidade.

Ao considerar a capacidade individual da burocracia e as diferentes áreas de atuação no governo, deve-se admitir que há diferenças em sua forma de agir em questões políticas (políticas públicas relativas ao setor) e nos tipos de política formuladas e implementadas. Diante do exposto, pode-se pensar em verificar as capacidades individuais da burocracia por meio da análise da estruturação e das características dos servidores públicos atinentes ao agronegócio?

Desse modo, o objetivo deste trabalho é analisar a capacidade individual dos burocratas no âmbito do MAPA do governo federal brasileiro enquanto meio para o entendimento da assertividade das ações governamentais empreendidas no setor rural.

Para cumprir esse objetivo, de maneira a responder à questão de pesquisa, o presente trabalho encontra-se estruturado em quatro partes, além desta introdução. Na primeira, de natureza teórica, é apresentada a construção do modelo teórico-analítico empregado, com destaque para a adaptação dos conceitos discorridos em Wu, Ramesh e Howlett (2015), que versam sobre as capacidades governamentais. A metodologia é apresentada no terceiro tópico, no qual se elaboram os construtos analíticos de interesse. No quarto tópico, são apresentados os resultados, bem como as discussões deles originadas. Em seguida, são apontadas as conclusões principais.

\section{REVISÃO TEÓRICA}

\subsection{0 papel da burocracia na capacidade de geração de políticas públicas}

A Constituição Cidadã, como é chamada a Constituição da República Federativa do Brasil (1988), ampliou as atribuições do Estado em relação aos problemas enfrentados pela população, especialmente em relação a uma maior proteção social, bem como delimitou as atribuições interfederativas mediante uma maior descentralização de recursos e responsabilidades (Castro \& Ribeiro, 2009; Souza, 2001). Aliado a esse contexto, já em meados da década de 1990, percebeu-se que seria necessário "modernizar" o aparato governamental em vista da entrega de melhores resultados à população (Bresser-Pereira, 1998). Nesse contexto, surge a denominada reforma administrativa gerencial, que colocaria no centro das discussões a necessidade de uma maior eficiência na gestão pública central.

Na visão de Paula (2005), o gerencialismo implicou a incorporação de diretrizes administrativas comuns ao escopo das empresas de capital pela esfera da administração pública. Sob o modelo gerencial, a eficiência, como já adiantado, tornou-se um norte, uma vez que o cidadão passou a ser visto não apenas como usuário, mas também como cliente.

\footnotetext{
${ }^{2}$ A descontinuidade relaciona-se ao prazo de análise e à aprovação de uma nova proposta, quando da finalização do projeto anterior.

${ }^{3}$ A Conab é uma empresa pública ligada ao MAPA.
} 
Dessa forma, a oferta de serviços deveria suprir as necessidades dos indivíduos com a otimização do uso de recursos públicos e a modernização do aparato estatal. Como resultado dessa perspectiva, Pacheco (2002) aponta que houve a necessidade de uma maior capacitação dos servidores públicos, incluindo a instrução formal, uma vez que o nível de escolaridade preponderante não se mostrava pertinente aos anseios da reforma gerencial.

Os níveis de eficiência e assertividade (eficácia) nas ações empreendidas pelos atores governamentais passaram, a partir de então, a ser um guia na análise de qualquer ação. Apesar disso, dadas algumas incongruências do modelo gerencial ${ }^{4}$, ainda são diversos e, portanto, pouco elucidativos os meios de se conceituar e/ou analisar a eficácia no escopo da gestão pública, incluindo-se nesse cenário a capacidade de os atores entregarem serviços que atendam ao que é demandado pela sociedade de maneira equitativa.

Wu et al. (2015) salientam que existiriam três bases para a elaboração de intervenções governamentais eficazes, eficientes e equitativas: ${ }^{5}$ analítica, operacional e política. Essas bases se manifestariam em três níveis: individual, organizacional e sistêmico. No Quadro 1, são elencadas as principais características dessas bases analíticas em relação aos seus distintos níveis de manifestação.

\section{QUADRO 1 MODELO INTER-RELACIONADO DE ANÁLISE DA CAPACIDADE GOVERNAMENTAL}

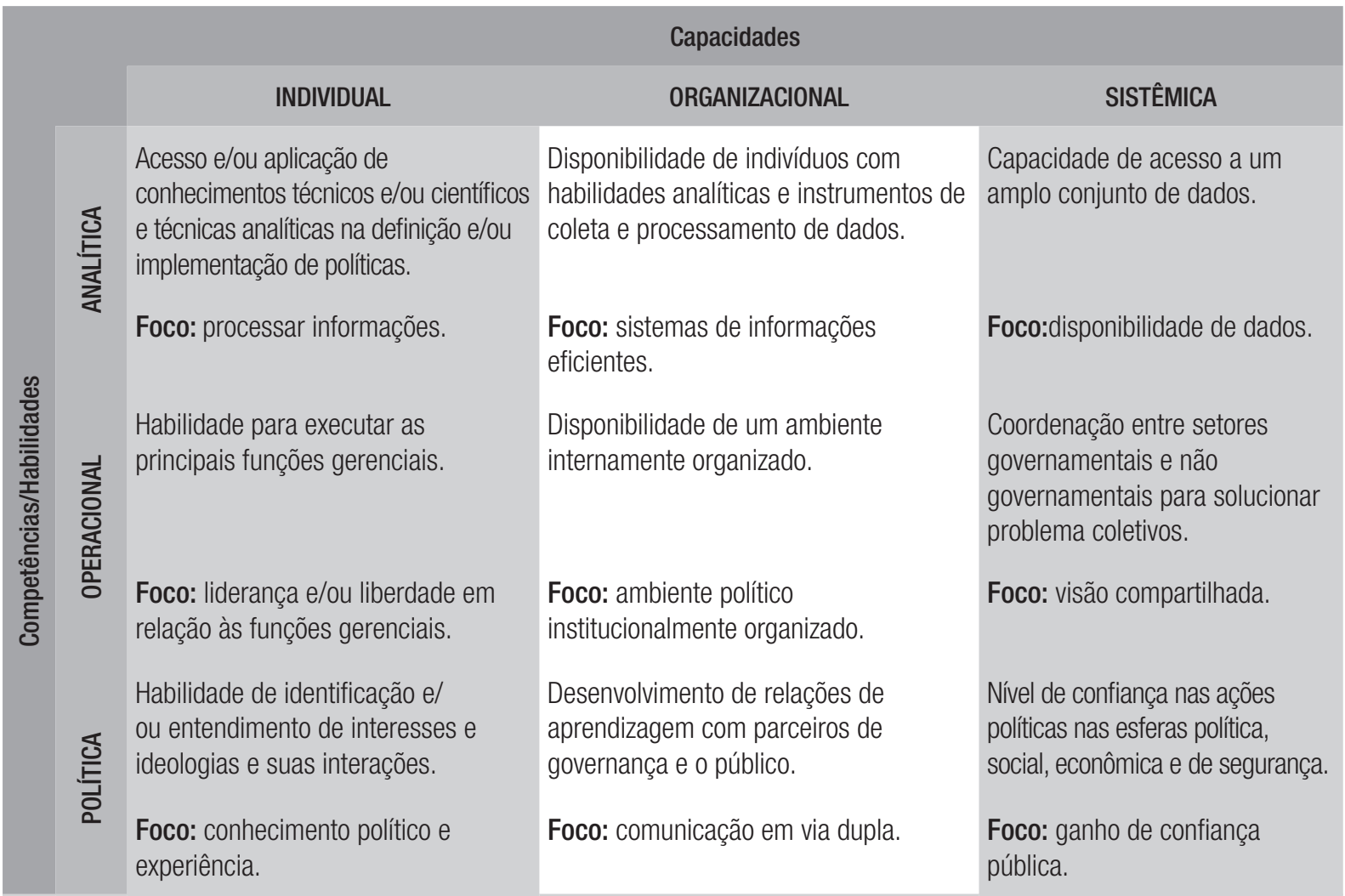

Fonte: Adaptado de Wu et al. (2015).

\footnotetext{
${ }^{4}$ Paula (2005) indica que os controles sociais preceituados pelo modelo gerencial não se mostraram efetivos na realidade, igualmente o caso do desapego à burocracia, na medida em que houve apenas uma idealização da chamada orientação ao serviço público.

${ }^{5} \mathrm{O}$ conceito cunhado por Wu et al. (2015), policy capacity, aqui será utilizado como capacidade da gestão pública de elaborar e implementar políticas públicas eficazes, eficientes e equitativas.
} 
Ainda que o modelo inter-relacionado apresentado pelo Quadro 1 dê ênfase a uma base multinível em relação às capacidades, é preciso salientar que qualquer ação empreendida no escopo da administração pública se depreende, preliminarmente, pelo nível individual (linha mais densa do quadro). Este nível seria aquele em que atores sociais cooperativamente conjugam esforços em uma configuração pública (F. A. Nigro \& L. G. Nigro, 1970). Adicionalmente, conforme salientado por Lavee, Cohen e Nouman. (2018), uma das principais causas da ineficiência de ações governamentais resulta do afastamento dos burocratas dos programas políticos (nível organizacional), criando ruídos e, consequentemente, problemas.

Sob essa perspectiva, Baekgaard et al. (2018) são enfáticos ao evidenciar o papel ativo dos burocratas em todas as etapas das decisões governamentais, o que confronta a ideia de que esses atores são meros implementadores de políticas públicas. Diante de um cenário complexo, os burocratas interpretam os dados e informam aos tomadores de decisão as melhores ações a serem traçadas na conformação da agenda das políticas públicas (Workman, 2015). Percebe-se, por conseguinte, o importante papel que a burocracia, no nível da capacidade individual, tende a exercer no contexto da tomada de decisão e dos resultados alcançados na esfera pública.

\subsection{A caracterização do perfil da burocracia no contexto do governo federal brasileiro}

Com as mudanças advindas com a Constituição de 1988, Abrúcio e Loureiro (2018) salientam que houve um crescimento da burocracia estatal brasileira. Complementarmente, programas de investimento em infraestrutura, implementados em meados da primeira década dos anos 2000, ampliaram a demanda de burocratas com habilidades técnicas (Freire, Knop, Alves, Cavalcante \& Palotti, 2017). Esse conjunto amplificado de burocratas da esfera federal brasileira pode ser analisado, na visão de Pires (2012), de duas naturezas: tático-gerencial, entendida como a compreensão das diretrizes estratégicas e sua explicação aos atores dos níveis operacionais; e técnico-política, concebida como a capacidade de negociação com os atores de interesse; bem como sob três níveis em relação à posição ocupada pelos servidores públicos: nível de rua, médio, e alto escalão.

\section{FIGURA 1 PERSPECTIVAS ANALÍTICAS DOS NÍVEIS E DO PAPEL DOS BUROCRATAS NA GESTÃO} PÚBLICA

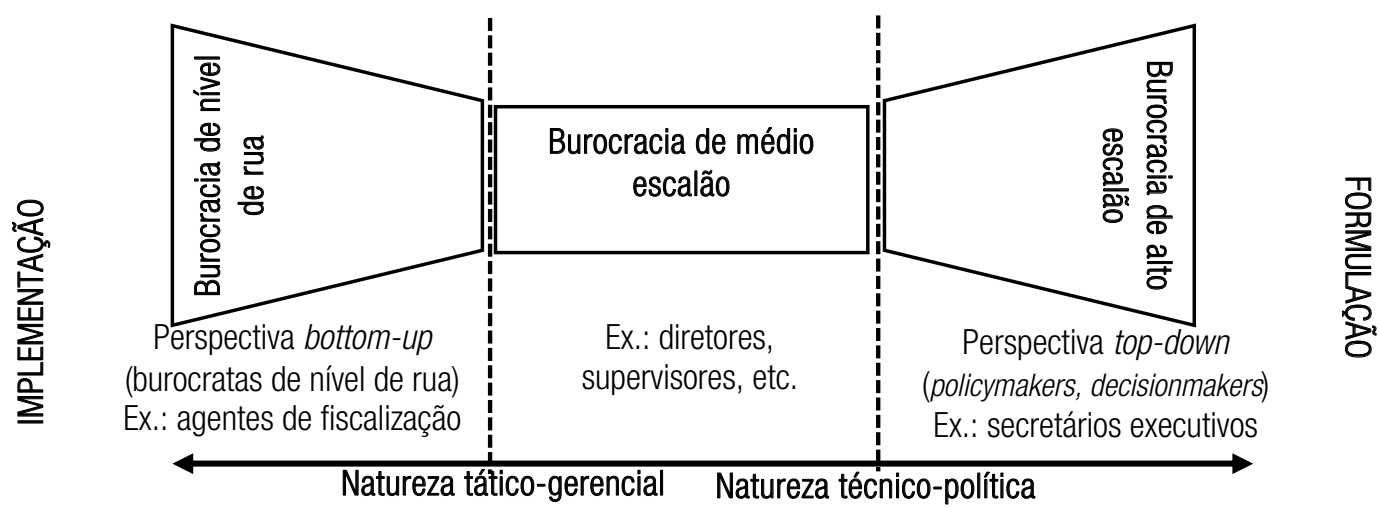

Fonte: Elaborada pelos autores com base em Pires (2012). 
Na burocracia de nível de rua, é no estrato do aparato governamental que ocorre o refinamento do efeito da política pública sobre o cidadão. De forma mais clara, Lipsky (2019) chama a atenção para o fato de que, na figura dos servidores nesse nível de burocracia, o cidadão encontra o governo, o que coloca esses profissionais em posição crítica em relação ao sucesso, ou não, de determinadas ações.

No outro extremo estão os burocratas do chamado alto escalão, que são concebidos por D’Araújo (2009, p. 18) como aqueles servidores que, ao lado dos servidores ocupantes de cargos de natureza especial e dos agentes políticos, conformam "a elite dirigente que governa o país". No nível intermediário, o burocrata de médio escalão, conforme salientam Cavalcante e Lotta (2015), em uma perspectiva contingente, a depender do setor e da política, pode atuar com elevado nível de autonomia em relação ao processo decisório ou não. Quanto maior é o estrato situacional, maiores são as atribuições relacionadas à tecnicidade política; quanto mais próxima do nível de rua, maiores as exigências de características tático-gerenciais.

Lopez et al. (2014) indicam que, além desses diferentes níveis hierárquicos, duas outras distinções podem ser encontradas na conjuntura de pessoal da esfera governamental, quais sejam: relacionadas à natureza do vínculo ou à categorização dos cargos em comissão. No aspecto da natureza do vínculo, encontram-se os servidores de carreira, ou efetivos, que são aqueles incorporados ao aparato governamental mediante aprovação em concurso público, possuidores de estabilidade. $\mathrm{Na}$ categorização dos cargos em comissão, estão aqueles servidores passíveis de serem desligados a qualquer tempo do serviço público.

Especificamente em relação aos cargos de classes média e elevada, enquadrados nos chamados cargos de Direção e Assessoramento Superior (DAS), há uma discriminação em seis níveis hierárquicos distribuídos em duas categorias - direção e assessoramento -, aos quais os ocupantes de tais posições estão sujeitos. Conforme se verifica nas informações do Quadro 2, os cargos de confiança, especificamente no escopo do MAPA, órgão responsável por congregar as atribuições atinentes à intervenção governamental ao setor rural brasileiro, abarcavam seis níveis de direção (DAS 101) e cinco de assessoria (DAS 102) no ano de 2018. Tanto os cargos de direção quanto os de colaboração podem ser ocupados por servidores de carreira e por burocratas sob contratação temporária. 


\section{QUADRO 2 DISCRIMINAÇÃO DOS CARGOS DE CONFIANÇA NO CONTEXTO DO MAPA - 2018}

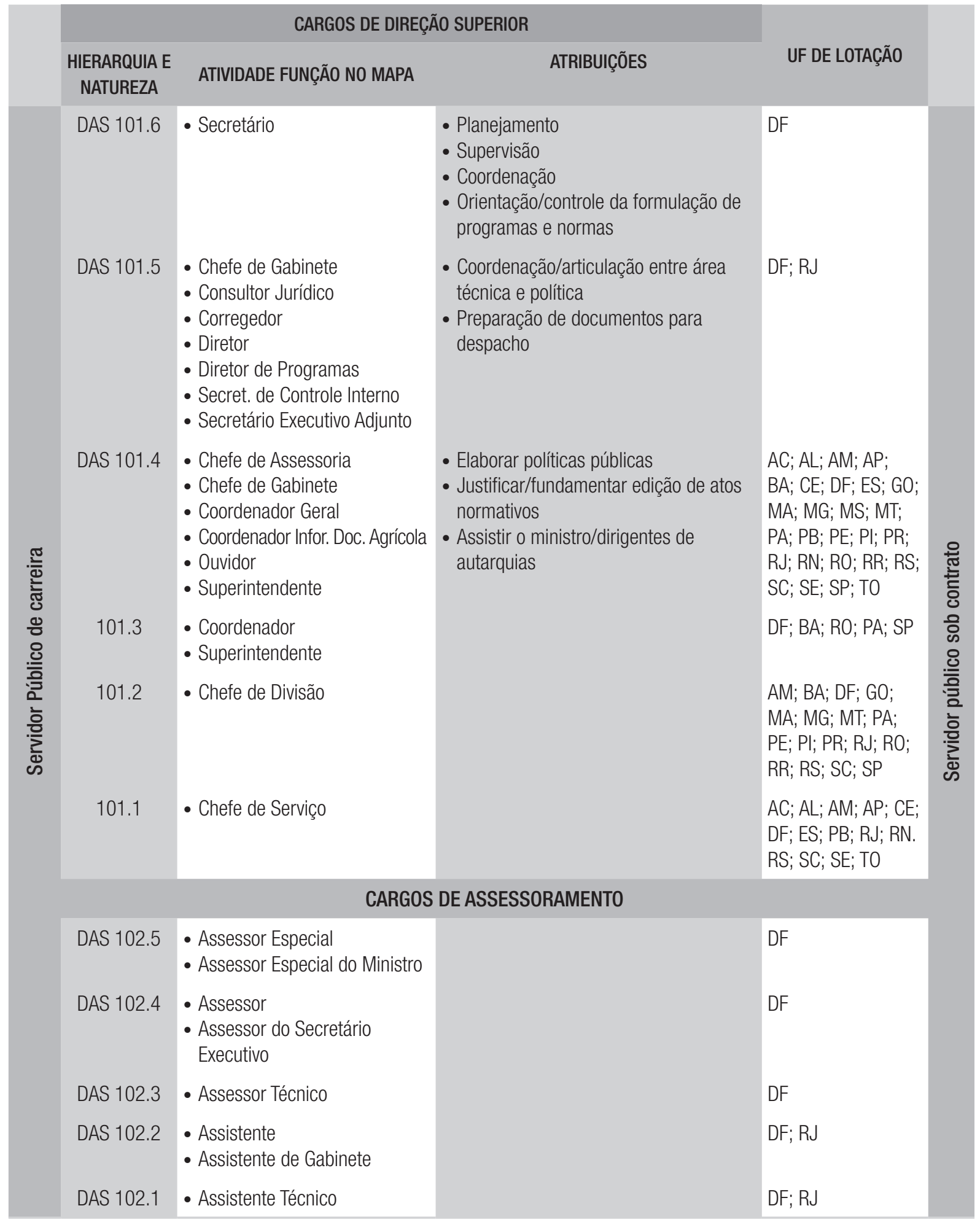

Fonte: Adaptada de Lopez et al. (2014) e dados da pesquisa. 
Ainda não há consenso na literatura quanto à melhor forma de distribuição de burocratas contratados e servidores de carreira (efetivos) que ocupam os cargos de nível superior. D’Araujo (2009), por exemplo, considera que, quando existe um número elevado de cargos a serem preenchidos por indicação do presidente (cargos de confiança), como é o caso do Brasil, existiriam duas perspectivas negativas: alta centralidade e falta de transparência nos processos de seleção.

Esse cenário está em confronto com o que preza os princípios de uma boa gestão pública, uma vez que a seleção pode não ocorrer por mérito, no caso dos servidores não efetivos da carreira pública. Lopez (2017) salienta que a ampliação no número de ocupantes nos cargos comissionados superiores é comumente considerada um problema, uma vez que, no contexto brasileiro, há um recorrente uso de indicações partidárias para essas posições. Este fato, juntamente com a coalizão política existente na esfera federal, leva a uma alta rotatividade ${ }^{6}$, o que acaba por prejudicar o sequenciamento das ações empreendidas.

Em contraposição a essa concepção, Praça, Lotta e Oliveira (2012) verificaram que as posições de cargos de comissão não são necessariamente alteradas por mudanças de ministros, visto que o fator preponderante em muitos casos é a experiência dos burocratas. Discorrendo ainda no contexto da expertise dos burocratas ocupantes de cargo de confiança, Bresser-Pereira (1996) já salientava que, como há uma flexibilidade na escolha dos ocupantes de cargos dessa natureza, o mérito passaria, em tese, a ser um norte na seleção, com consequente opção pelos quadros mais aptos.

É preciso delimitar que existe legislação que volta a autolimitar ${ }^{7}$ o inciso V do Art. 37 da Constituição Federal de $1988^{8}$, justamente o preceito constitucional relacionado a essa flexibilidade indicada por Bresser-Pereira (1996). A primeira legislação nesse sentido foi o Decreto $n^{\circ}$ 5.497, de 21 de julho de 2005 (2005).

Esse primeiro decreto estipulou que os servidores de carreira (efetivos) ocupariam percentuais mínimos nas posições de direção e assessoramento superior, em cargos de DAS, nas seguintes delimitações: $75 \%$ em cargos DAS 1, 2 e 3; e 50\% nos DAS 4. Posteriormente, houve um novo decreto, o de número 9.021 de novembro de 2017, alterando alguns dispositivos do ordenamento predecessor. As principais mudanças advindas com esse segundo decreto foram a inclusão de $60 \%$ de pessoal efetivo em relação ao conjunto total de servidores para as posições DAS 5 e 6, e 50\% nos demais níveis (DAS 1, 2, 3 e 4).

\footnotetext{
${ }^{6}$ Cada mudança ministerial ativa o carrossel burocrático de novas nomeações (e exonerações) em todos os níveis de DAS” (Lopez, 2017, p. 31).

${ }^{7}$ Denominação dada por Rezende (2017).

${ }^{8} \mathrm{O}$ referido inciso indica que "[...] as funções de confiança, exercidas exclusivamente por servidores ocupantes de cargo efetivo, e os cargos em comissão, a serem preenchidos por servidores de carreira nos casos, condições e percentuais mínimos, previstos em lei, destinam-se apenas às atribuições de direção, chefia e assessoramento" (Constituição da República Federativa do Brasil, 1988).
} 


\subsubsection{Estrutura burocrática governamental e 0 agronegócio brasileiro}

A definição de agenda em relação às políticas e programas governamentais no escopo do agronegócio brasileiro é questão estratégica para a gestão pública, dada a relevância da área para o desenvolvimento econômico do país (Bacha, 2004; Gonçalves, Alves, Shikida \& Staduto, 2009; Filippi, Guarnieri, Carvalho, Reis \& Cunha, 2019). O agronegócio tem respondido ao longo dos últimos anos por um papel importante na balança comercial e, por decorrência, uma considerável influência na constituição do Produto Interno Bruto (PIB), ou seja, na geração de riqueza ao Brasil (Castro, Barros, Almeida, Gilio \& Morais, 2020; Moreira et al., 2016).

Abbey, Baer e Filizzola (2006) discorrem que foram decisões na esfera pública, especialmente a política de crédito rural e investimento em pesquisa e desenvolvimento, implementadas na década de 1960, que culminaram com a ampliação da produtividade da agricultura brasileira. Todavia, com as mudanças estruturais pelas quais passou o Brasil no início da década de 1990, destacando-se o processo de abertura comercial, houve uma reorganização do setor produtivo do agronegócio, ensejando que os mais diversos atores passassem a buscar no governo um maior atendimento de seus interesses. Esse contexto acabou por influir na definição da agenda relacionada à área e fez emergir uma ampliação nas linhas de financiamento, seguro rural, etc. (Machado, 2009).

No que tange ao papel da burocracia no contexto do MAPA, que é o órgão setorial no âmbito do governo federal brasileiro responsável pela definição de ações relacionadas ao setor rural, poucos estudos têm sido realizados. O trabalho de Costa (1993), por exemplo, indicou que determinados funcionários permaneciam nos seus cargos de direção por longos períodos em virtude dos conhecimentos que possuíam em relação à articulação com lobbies e com as bancadas congressistas. Essa percepção é contraditada por Lopez e Praça (2015), ao afirmar que as superintendências estaduais do MAPA constituem um dos setores do governo federal de maior disputa por indicação política e/ou partidária, dada a capacidade de influência e, por consequência, de projeção de parlamentares em suas bases.

Medeiros et al. (2005), em estudo sobre ações de alterações estruturais na organização do MAPA, apontam que em 2005 houve pretensões de implementar processos de disseminação das prioridades e metas estratégicas aos servidores, de maneira a otimizar a eficácia das ações. Porém não há maiores indicativos acadêmicos relacionados aos efeitos dessas intervenções, a não ser o fato identificado por Vicari (2020) sobre ocorrência, nessa época, de uma reaproximação com o empresariado, em virtude da consolidação das câmaras setoriais, de composição de cargos e ganhos de capacidade administrativa. Verifica-se, portanto, que analisar as características da burocracia no escopo do MAPA é condição relevante para a compreensão da forma como se situa e se estrutura esse setor governamental estratégico na gestão pública brasileira.

De 2016 a 2019, de maneira sintética, o MAPA apresentava a estruturação conforme o Quadro 3. 


\section{QUADRO 3 ESTRUTURA REGIMENTAL DO MAPA VIGENTE DE 2016 A 2019}

\begin{tabular}{|c|c|c|c|c|}
\hline $\begin{array}{l}\text { ASSISTÊNCIA } \\
\text { IMEDIATA AO } \\
\text { MINISTRO }\end{array}$ & SECRETARIAS & $\begin{array}{c}\text { UNIDADES } \\
\text { DESCENTRALIZADAS }\end{array}$ & $\begin{array}{c}\text { ORGÃOS } \\
\text { COLEGIADOS }\end{array}$ & ENTIDADES VINCULADAS \\
\hline $\begin{array}{l}\text { - Gabinete do } \\
\text { Ministro } \\
\text { - Assessoria } \\
\text { Especial de } \\
\text { Controle Interno } \\
\text { - Secretaria } \\
\text { Executiva } \\
\text { - Corregedoria } \\
\text { - Escola Nacional } \\
\text { de Gestão } \\
\text { Agropecuária } \\
\text { - Departamento de } \\
\text { Administração } \\
\text { - Departamento } \\
\text { da Comissão } \\
\text { Executiva do } \\
\text { Plano da Lavoura } \\
\text { Cacaueira }\end{array}$ & $\begin{array}{l}\text { - Secretaria de } \\
\text { Aquicultura e Pesca } \\
\text { - Secretaria } \\
\text { de Defesa } \\
\text { Agropecuária } \\
\text { - Secretaria de } \\
\text { Mobilidade Social, } \\
\text { do Produtor Rural e } \\
\text { do Cooperativismo } \\
\text { - Secretaria de } \\
\text { Política Agrícola } \\
\text { - Secretaria } \\
\text { de Relações } \\
\text { Internacionais do } \\
\text { Agronegócio }\end{array}$ & $\begin{array}{l}\text { - Superintendências Federais } \\
\text { de Agricultura, Pecuária e } \\
\text { Abastecimento } \\
\text { - Laboratórios Nacionais } \\
\text { Agropecuários } \\
\text { - Superintendências } \\
\text { Regionais de } \\
\text { Desenvolvimento da } \\
\text { Lavoura Cacaueira } \\
\text { - Terminais Pesqueiros } \\
\text { Públicos } \\
\text { Distritos de Meteorologia }\end{array}$ & $\begin{array}{l}\text { - Comitê Gestor } \\
\text { Interministerial } \\
\text { do Seguro Rural } \\
\text { (CGSR) } \\
\text { - Comissão } \\
\text { Coordenadora da } \\
\text { Criação do Cavalo } \\
\text { Nacional (CCCCN) } \\
\text { - Comissão Especial } \\
\text { de Recursos (CER) } \\
\text { - Conselho } \\
\text { Deliberativo da } \\
\text { Política do Café } \\
\text { (CDPC) } \\
\text { - Conselho } \\
\text { Interministerial do } \\
\text { Açúcar e do Álcool } \\
\text { (CIMA) } \\
\text { - Conselho Nacional } \\
\text { de Aquicultura e } \\
\text { Pesca (CONAPE) } \\
\text { - Conselho Nacional } \\
\text { de Política Agrícola } \\
\text { (CNPA) }\end{array}$ & $\begin{array}{l}\text { Autarquia } \\
\text { - Instituto Nacional de } \\
\text { Colonização e Reforma } \\
\text { Agrária (INCRA) } \\
\text { Empresas Públicas } \\
\text { - Empresa Brasileira de } \\
\text { Pesquisa Agropecuária } \\
\text { (Embrapa) } \\
\text { - Companhia Nacional de } \\
\text { Abastecimento (Conab) } \\
\text { Sociedade de Economia } \\
\text { Mista } \\
\text { - Centrais de } \\
\text { Abastecimento de } \\
\text { Minas Gerais S.A. } \\
\text { (CEASA/MG) } \\
\text { - Companhia de } \\
\text { Armazéns e Silos do } \\
\text { Estado de Minas Gerais } \\
\text { S.A. (CASE/MG) } \\
\text { - Companhia de } \\
\text { Entrepostos e Armazéns } \\
\text { Gerais de São Paulo } \\
\text { (CEAGE/SP) }\end{array}$ \\
\hline
\end{tabular}

Fonte: Decreto ${ }^{\circ}$ 8.852, de 20 de setembro de 2016 (2016).

As informações apresentadas no Quadro 3 permitem identificar a existência de um staffburocrático mais próximo do ministro, secretarias com atribuições relacionadas às mais diversas áreas do setor rural, unidades descentralizadas - que caracterizam a capilaridade do órgão nas unidades da federação - e entidades vinculadas, estas últimas compondo o conjunto de empresas e autarquias ligadas ao ministério. Ademais, havia ainda, no período em análise, órgãos colegiados, cujas atribuições versavam, basicamente, sobre a definição de diretrizes e prioridades e encaminhamento de demandas relacionadas às respectivas áreas de atuação do ministério. 


\section{METODOLOGIA}

A presente pesquisa, de natureza quantitativo-descritiva, visou, em um primeiro momento, analisar diferenças na rotatividade da burocracia em posições de confiança no contexto do MAPA. O conceito de rotatividade, bem como a metodologia utilizada alinham-se ao apresentado em Lopez et al. (2014, p. 445), que indicam “[...] a relação entre o número de funcionários demitidos e o número de funcionários contratados". Trata-se, portanto, de um índice referente a substituição de servidores.

Para a observação da rotatividade, utilizou-se uma análise em painel entre os anos de 1999 e de $2012^{9}$. Há de se ressaltar que o espaço temporal da proxy de rotatividade diverge do lapso das demais variáveis, uma vez que, conforme salientado por Lopez et al. (2014), a partir de 1999 os dados são robustamente confiáveis. O ano final, 2012, é o último com a existência de informações sequenciais contidas nos microdados disponibilizados pelo Instituto de Pesquisas Econômicas e Aplicadas (Ipea), característica necessária a essa proxy.

Posteriormente, com a utilização do teste de amostras independentes Mann-Whitney $\mathrm{U}^{10}$, intentouse verificar distinções estatisticamente relevantes nos dados de servidores do MAPA entre dois cortes temporais - foram considerados os anos de 1998 e o de 2018. Na visão de Field (2009), quando se pretende comparar as médias de dois grupos independentes para um condicionamento mútuo, especificamente quando esses grupos não assumem condição de normalidade, o teste estatístico mais aconselhável é o de Mann-Whitney U. Trata-se, desta feita, de uma análise de dados secundários em seção cruzada, comumente realizada em pesquisas no escopo da análise estrutural da gestão pública, como se verifica em Bogoni, Nelson e Beuren (2011).

Foi considerado o ano de 1998 porque este corresponderia ao período em que ocorreu uma redução de práticas protecionistas por parte do governo federal, conforme salientam I. V. Lopes e M. D. R. Lopes (2010), com considerável impacto no agronegócio e, por inferência, na gestão pública relacionada a esse setor. Além disso, esse marco de 1998 foi o ponto inicial para mudanças no escopo do MAPA, que refletiriam, no ano seguinte, na criação do Ministério do Desenvolvimento Agrário $(\mathrm{MDA})^{11}$, por exemplo. O ano de 2018, como ponto de contraposição das análises, foi escolhido por representar um período em que houve modificações estruturais nas políticas do MAPA, com destaque para o Agro+, que focalizou procedimentos específicos de desburocratização ${ }^{12}$.

A principal fonte de dados relacionada ao que aqui se denominou de burocracia foi o sistema que gerencia as informações atinentes ao quadro de funcionários públicos do governo federal, o Sistema Integrado de Administração de Pessoal (SIAPE). Insta destacar que a concepção de classificação adotada foi o conjunto de servidores ocupantes de posições DAS no MAPA.

Como esse sistema é de acesso restrito, a análise dos dados foi possível com a colaboração do Ipea, que, mediante pactuação de termo formal de garantia de sigilo das informações pessoais ${ }^{13}$, forneceu

\footnotetext{
${ }^{9} \mathrm{O}$ espaço temporal da rotatividade diverge daquele levado em consideração nas outras variáveis de interesse, uma vez que, conforme salientado por Lopez et al. (2014), é a partir de 1999 que os dados são robustamente confiáveis.

${ }^{10}$ A opção pelo teste de Mann-Whitney U deu-se em virtude de o teste de normalidade Smirnov-Kolmogorov indicar que todas as proxies de análise do construto possuem distinção de uma distribuição normal.

${ }^{11}$ Em 2019, diante da reestruturação da organização do governo federal, o MDA foi extinto e suas atribuições retornaram ao MAPA.

${ }^{12}$ Lançado em dezembro de 2017 pelo então ministro da agricultura Blairo Maggi.

${ }^{13}$ A autorização está relacionada apenas a dados agregados, preservando informações de caráter pessoal dos servidores.
} 
o banco de dados do período considerado. A autorização para a utilização dos dados está atrelada a divulgação agregada das informações.

Como forma da verificação da capacidade de geração de políticas públicas na unidade de análise de interesse, tendo como base o conceito discutido por Wu et al. (2015), apresentado no Quadro 1, foram elencadas discricionariamente - considerando os dados da base do SIAPE, bem como as informações contidas nos microdados disponibilizados pelo Ipea - as variáveis de interesse (proxy) apresentadas no Quadro 4. Intentou-se, com a seleção dessas proxies, criar um construto que possibilitasse a análise da capacidade individual.

\section{QUADRO 4 VARIÁVEIS DE INTERESSE E BASES ANALÍTICAS DAS CAPACIDADES INDIVIDUAIS DA BUROCRACIA DO MAPA}

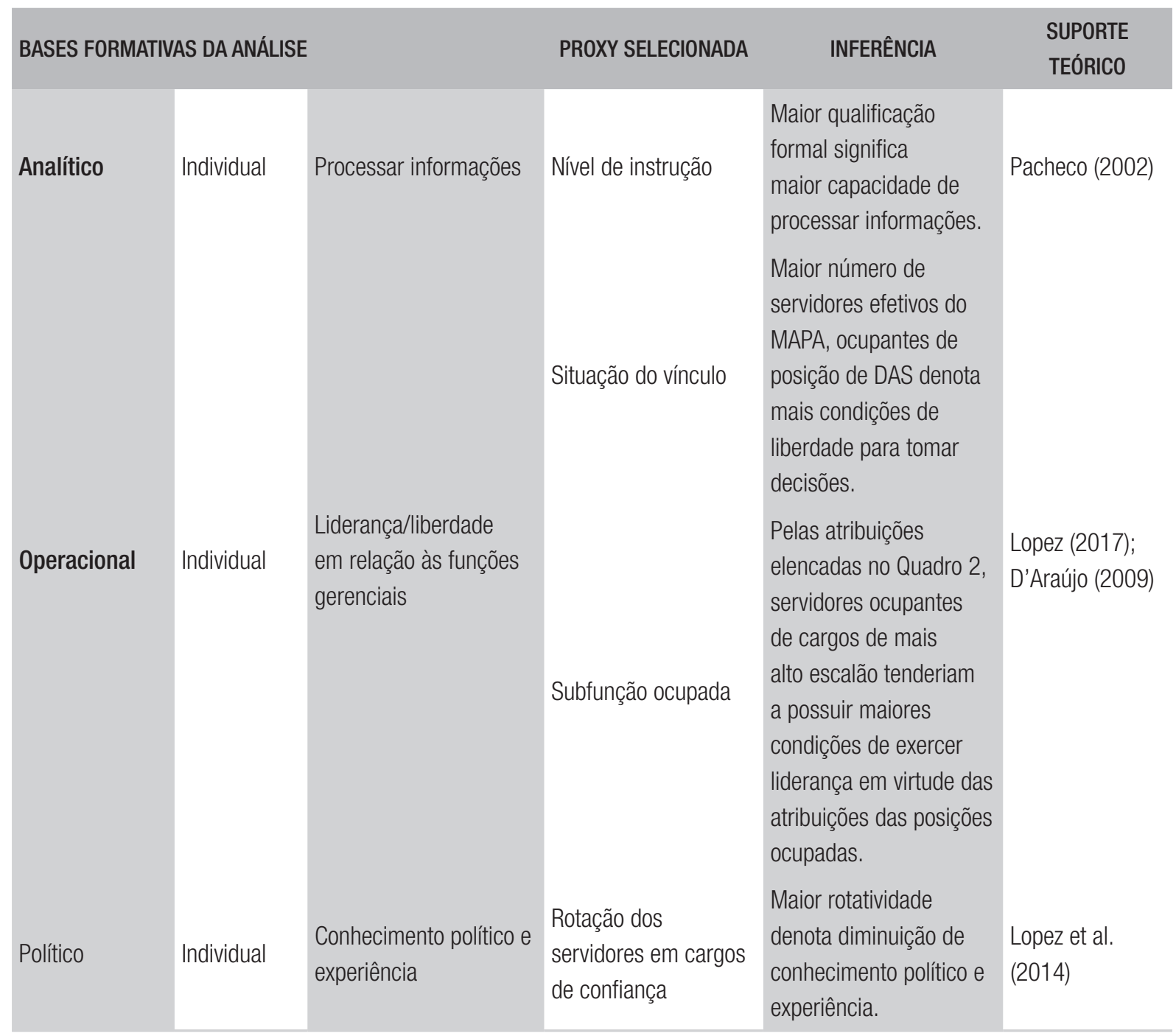

Fonte: Dados da pesquisa. 
A despeito do fato de Wu et al. (2015) terem apontado que a capacidade para a elaboração de intervenções governamentais eficazes, eficientes e equitativas esteja atrelada a um conjunto multidimensional - individual, organizacional e sistêmico -, o presente trabalho focalizará apenas o condicionante individual. Esta escolha atrela-se à assunção dos indicativos de Baekgaard et al. (2018), Lavee et al. (2018), F. A. Nigro e L. G. Nigro (1970) e Workman (2015), como já discorrido, de que as características da burocracia ao nível individual dos atores (burocratas) são consideradas a espinha dorsal de qualquer estruturação na esfera de governo.

\section{RESULTADOS E DISCUSSÃ0}

\subsection{Rotatividade dos servidores DAS no MAPA}

Conforme já adiantado, o cálculo da rotatividade segue o padrão apresentado em Lopez et al. (2014). Esse padrão leva em consideração quatro variáveis, tomando como referência o número total de servidores ocupantes de cargos DAS e o ano anterior. Os enfoques, baseados nessa estruturação, se dão em relação a: número de servidores que não tiveram a sua função alterada; número de servidores que sofreram alteração em suas posições (promoção ou rebaixamento); servidores contratados; e número de servidores demitidos. O Gráfico 1 evidencia a evolução da rotatividade dos ocupantes de cargos DAS no período compreendido entres os anos de 2000 e 2012.

\section{GRÁFICO 1 TOTAL DE FUNCIONÁRIOS OCUPANDO CARGO DE DAS NO MAPA (2000-2012)}

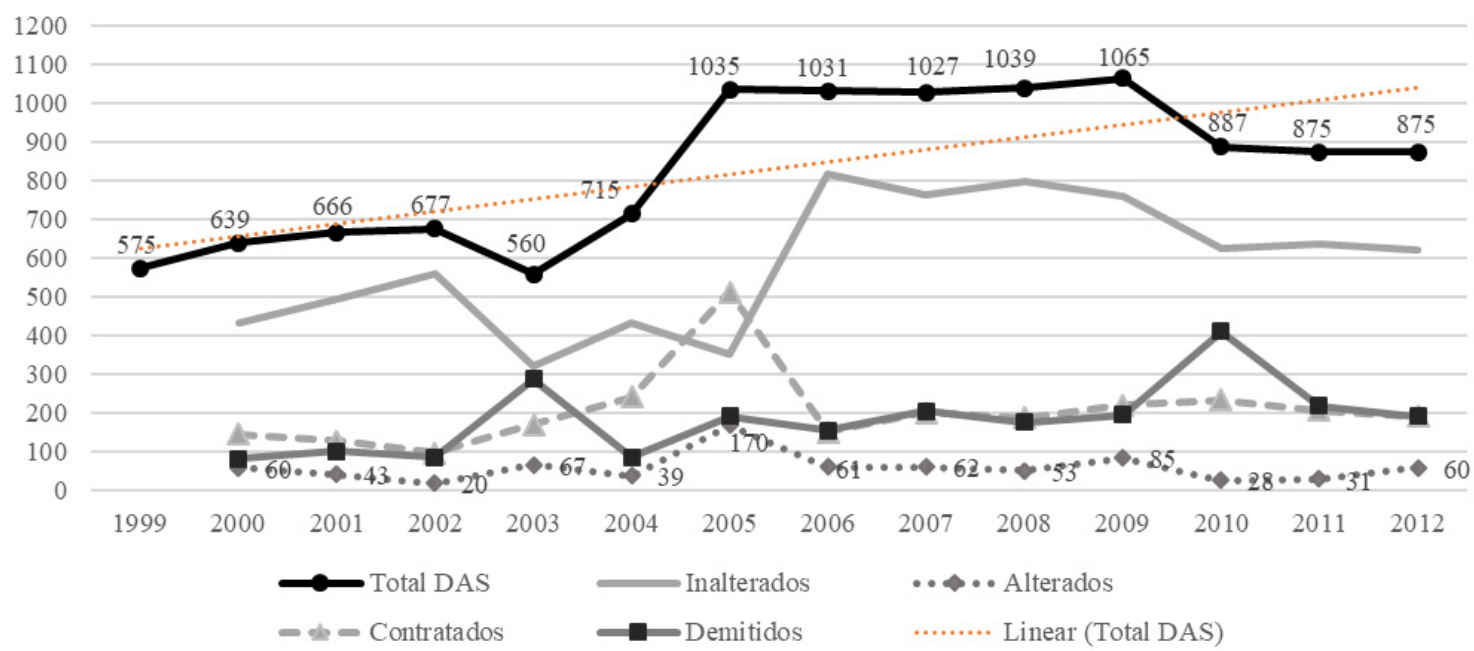

Fonte: Elaborado pelos autores com base nos dados do SIAPE. 
Pelo Gráfico 1, é possível verificar que os picos de maior alteração ascendente no conjunto total de servidores em comissão, entre os anos de 2000 e 2012, ocorreram entre 2003 e 2005. Esse crescimento foi o responsável por um índice de modificação (alteração) de cerca de 11\% em 2003 e 16\% em 2005. A considerar a premissa proposta por Wu et al. (2015) em relação a capacidade política, esse cenário de maior alteração no escopo do MAPA seria prejudicial, uma vez que tenderia a reduzir a expertise do quadro técnico do ministério na identificação de atores-chave dentro e fora da estrutura estatal, suas relações, bem como nos conflitos de escolha necessários à construção de acordos.

Em 2003, uma alteração já era esperada no número de desligamentos. É patente que, na instauração de um novo governo central, especialmente quando existe uma reorganização da base da presidência ${ }^{14}$, ocorra a substituição do ministro, indicando-se um ocupante de confiança do presidente, visão contrária ao que preceituam Praça, Freitas e Hoepers (2012), visto que acarreta modificações no quadro de servidores, nos cargos em questão.

Ademais, outra possibilidade que enseja mudança, não apenas no cargo de ministro, mas em cargos de níveis mais elevados, é a alteração na coalizão político-partidária que deu suporte aos candidatos. Especialmente em relação ao ano de 2003, sabe-se que houve o início de um novo governo na esfera federal e que essas alterações seriam igualmente esperadas.

O ano de 2005 chama atenção pela oscilação da linha de contratações. Essa mudança pode ser explicada pela chamada reforma administrativa ${ }^{15}$, efetivada em fevereiro do referido ano e implementada pelo então ministro Roberto Rodrigues ${ }^{16}$. Em síntese, a reforma ampliou e criou secretarias, reestruturou as então delegacias estaduais, que passaram a ser chamadas de superintendências, e criou órgãos de assessoria.

Medeiros et al. (2005) salientam que, no ano de 2005, houve um esforço para otimizar a eficiência por intermédio de diagnósticos de autoavaliação, consultas internas e externas. Assim, a referida reforma, possivelmente, é o fator explicativo do pico ascendente de servidores "contratados" ${ }^{17}$ no período. Essas modificações foram implementadas sob o amparo do Decreto no 5.351 de 21 de janeiro de 2005 (2005).

No Gráfico 1, verifica-se outra inflexão de curva no ano de 2010, quando se percebe uma redução no número absoluto de servidores ocupantes de posições DAS. Observa-se, ainda, no escopo dessa inflexão, que a redução do número absoluto foi resultante de demissões (desligamentos de servidores em posições DAS).

Insta destacar que, nesse período, o MAPA passou por uma reestruturação forçosa, uma vez que houve a mudança de ministros em decorrência de insatisfações por parte do partido político com influência de indicação no órgão ${ }^{18}$. Em abril de 2010 saiu o então ministro Reinhold Stephanes para a entrada de Wagner Rossi. Como a própria natureza da politização da coalizão partidária enseja,

\footnotetext{
${ }^{14}$ Assume a presidência da República Luiz Inácio Lula da Silva, do PT - após dois mandatos presidenciais consecutivos de Fernando Henrique Cardoso, do PSDB (01/01/1995 a 01/01/2003) -, que também governaria o país por dois períodos consecutivos (01/01/2001 a $01 / 01 / 2011$ ).

${ }^{15}$ Modificações efetivadas pelo Decreto n ${ }^{\circ} 5.351$ de 21 de janeiro de 2005 (2005).

${ }^{16}$ Ministro da Agricultura (2003-2006), sucedido por Luís Carlos Guedes Pinto (2006-2007). Seguiram-se Reinhold Stephanes, ministro de 2007 a 2010, sucedido por Wagner Rossi (2010 a 2011).

${ }^{17}$ O termo "contratado" não deve ser confundido com contratação externa, pois se trata de incorporação de um maior número de servidores em posições DAS.

${ }^{18}$ Com a chamada governança de coalizão, partidos políticos usualmente passam a deter influência na nomeação e, por decorrência, na permanência de seus indicados em setores governamentais. Ao fim e ao cabo, conforme salientam Cavalcante, Magalhães, Goellner e Palotti (2018), o chamado governo de coalizão é aceito pelo presidente como instrumento de formação de maioria no Congresso Nacional.
} 
conforme salientado em Lopez et al. (2014), alterações em diversos cargos ocorrem quando da modificação na posição máxima de supervisão, que, no caso em análise, diz respeito à posição de ministro de Estado. Obviamente que as posições com maior influência são aquelas de confiança, ou seja, livres de nomeação, como é o caso das DAS.

$\mathrm{Na}$ transição, Rossi aprofundou as relações com as bancadas partidárias. No início de 2011, trocou, devagar e lentamente, a equipe deixada por Stephanes. E abriu as portas do ministério para quase todos os aliados de Dilma. Nomeou secretários do PMDB, diretores do PR, do PTB e coordenadores ligados ao PP. Ruralistas emplacaram vários nomes na estrutura. A abertura de Rossi foi até criticada internamente pela cúpula do PMDB, que queria "porteira fechada" no ministério (Romero, 2011, p. A6).

Percebe-se que a política do chamado presidencialismo de coalizão é, possivelmente, fator responsável pela amplitude de rotatividade entre servidores públicos no período em análise. Em que pesem as capacidades individuais dos burocratas, sua performance pode variar, dadas as frequentes mudanças, o que acarretará influência nas capacidades de agir sobre os problemas políticos do setor. Na Tabela 1 apresentam-se a diferença absoluta e o percentual do decréscimo de servidores no período 2009-2010, por natureza hierárquica do cargo ocupado.

TABELA 1 VARIAÇÃO NO NÚMERO ABSOLUTO DE SERVIDORES POR NATUREZA DO CARGO (2009-2010)

\begin{tabular}{|c|c|c|c|c|}
\hline Níveis & 2009 & 2010 & Diferença absoluta & Variação (\%) \\
\hline DAS1 & 368 & 349 & 19 & $-5,2$ \\
\hline DAS2 & 316 & 268 & 48 & $-15,2$ \\
\hline DAS3 & 178 & 134 & 44 & $-24,7$ \\
\hline DAS4 & 145 & 97 & 48 & $-33,1$ \\
\hline DAS5 & 49 & 34 & 15 & $-30,6$ \\
\hline DAS6 & 9 & 5 & 4 & $-44,4$ \\
\hline Total & 1065 & 887 & 178 & $-16,7$ \\
\hline
\end{tabular}

Fonte: Elaborada pelos autores baseado nos dados do SIAPE. 
Pelas informações apresentadas na Tabela 1, é possível verificar que as reduções em posições ocorreram mais acentuadamente nos níveis mais elevados de DAS. Conforme já apresentado (ver Quadro 2), os níveis DAS 4, 5 e 6 possuem atribuições de elaboração e/ou assessoramento de políticas e programas governamentais. Eventualmente, e de maneira mais recorrente na mudança de governos e/ou ministros, a presidência da República via Casa Civil baixa decretos estipulando o quadro demonstrativo de cargos dos ministérios, bem como a estruturação regimental dos órgãos. Por meio desses decretos são estabelecidos departamentos, secretarias e outros. Complementarmente, esses decretos indicam possíveis reduções, ampliações e/ou remanejamentos de cargos entre órgãos do governo central para a supressão de outros órgãos ou para criação de novas estruturas.

Especificamente no ano de 2010, houve a publicação do Decreto no 7.127, de 4 de março de 2010 (2010), ainda sob a direção do ministro Reinhold Stephanes, que veio a revogar o Decreto $\mathrm{n}^{\text {o }} 5.351$ de 21 de janeiro de 2005 (2005) e o Decreto $\mathrm{n}^{\circ} 6.348$ de 8 de janeiro de 2008. (2008). O decreto publicado em março de 2010, assim como seus antecessores, delimitou uma nova reestruturação regimental, bem como o número de posições de confiança a serem ocupadas no âmbito do MAPA.

Por meio da referida determinação legal, algumas posições foram permutadas com a Secretaria de Gestão, do Ministério do Planejamento, Orçamento e Gestão ${ }^{19}$. Complementarmente, o art. 46 do referido ordenamento delega ao ministro a indicação dos cargos em comissão a serem ocupados por servidores de carreira, que ocorreria mediante processo de seleção interna ${ }^{20}$.

Em síntese, tais decretos almejavam regulamentar, à época dos fatos, o artigo 50 da Lei no 10.683 , de 28 de maio de 2003, que preceituava ao Poder Executivo a responsabilidade pela organização, e suas modificações, dos órgãos que compõem a administração pública, incluindo autarquias e fundações, bem como pela definição e/ou denominação de cargos.

\subsection{Caracterização dos servidores em relação à possibilidade de liderança e capacidade de processar informações}

Conforme indicado por Pacheco (2002) ${ }^{21}$, a partir de 1995, o quadro de burocratas, na esfera do governo federal brasileiro, passou a ser visto como um ativo estratégico, o que levou a qualificação instrucional a ser considerada como um aspecto-chave. Esse ponto, o da qualificação dos servidores públicos, passou a ser concebido como aspecto relevante no aprimoramento dos níveis de eficiência e assertividade nas ações empreendidas. Especificamente no contexto do MAPA, a estruturação descritiva de cargos de confiança, nos anos analisados, pode ser visualizada na Tabela 2.

\footnotetext{
${ }^{19} \mathrm{O}$ referido ministério foi incorporado ao Ministério da Economia a partir de 1 de janeiro de 2019.

${ }^{20}$ É necessário salientar que, conforme já apresentado, desde julho de 2005 havia determinação legal (Decreto no 5.497, de 21 de julho de 2005) indicando percentuais mínimos a serem atendidos com a ocupação de servidores efetivos em todo o governo central.

${ }^{21}$ Pacheco (2002, p. 81) indica que em 1995 mais de 60\% das posições de trabalho eram de nível médio e, portanto, as condições dos burocratas eram deficitárias nas "atividades de formulação e avaliação de políticas públicas, regulação e fomento [...]".
} 


\section{TABELA 2 TESTE DE MANN-WHITNEY U PARA A ESCOLARIDADE DE OCUPANTES DE DAS}

\begin{tabular}{|c|c|c|c|c|c|c|}
\hline \multirow[t]{2}{*}{ Nível de Escolaridade } & \multicolumn{2}{|c|}{1998} & \multicolumn{2}{|c|}{2018} & \multicolumn{2}{|c|}{$\begin{array}{c}\text { Teste Estatístico para } \\
\text { Amostras Independentes } \\
\text { Mann-Whitney U }\end{array}$} \\
\hline & Frequência & Percentual & Frequência & Percentual & Significância & Decisão \\
\hline $1^{0}$ grau incompleto $-4^{\mathrm{a}}$ séria completa & 2 & 0,4 & - & - & & \\
\hline $1^{\circ}$ grau completo - $8^{\mathrm{a}}$ série completa & 4 & 0,7 & 2 & 0,5 & & \\
\hline $2^{\circ}$ grau incompleto & - & - & 1 & 0,2 & & \\
\hline $\begin{array}{l}2^{\circ} \text { grau completo ou técnico } \\
\text { profissional. }\end{array}$ & 81 & 14,4 & 69 & 16,4 & & \\
\hline Nível médio & - & - & 1 & 0,2 & & \\
\hline Especialização & 11 & 2,0 & - & - & & Reter a \\
\hline Superior incompleto & - & - & 26 & 6,2 & ,798 & hipótese \\
\hline $\begin{array}{l}\text { Superior completo ou habilitação legal } \\
\text { equiv. }\end{array}$ & 447 & 79,4 & 300 & 71,3 & & nula \\
\hline Graduação nível superior & - & - & 1 & 0,2 & & \\
\hline Mestrado & 13 & 2,3 & 17 & 4,0 & & \\
\hline Doutorado & 4 & 0,7 & 4 & 1,0 & & \\
\hline Informação perdida (missing) & 1 & 0,2 & - & - & & \\
\hline Total & 563 & 100,0 & 421 & 100,0 & & \\
\hline
\end{tabular}

Nível de significância: 0,05; Intervalo de Confiança: 95\%.

Fonte: Dados da pesquisa.

Em relação às possíveis diferenças na capacitação instrucional dos ocupantes de cargos de comissão, o teste Mann-Withey U assume como hipótese nula a ser testada a mesma distribuição de escolaridade na comparação entre os dados de 1998 e 2018. Como se percebe na Tabela 2, a significância reportada é de 0,798, o que leva a reter a condição de que, estatisticamente, não houve modificações na estrutura da qualificação instrucional do quadro de servidores do MAPA no período analisado.

Do teste, e seu resultado, é possível vislumbrar duas inferências. A primeira é que essa possível não modificação se deve à própria natureza das atribuições dos cargos, uma vez que, mesmo nos níveis mais inferiores (DAS 1, 2 e 3), as posições ocupadas orbitam em torno de ações que usualmente requerem níveis de instrução superior. Dessa forma, em virtude das peculiaridades na ocupação de posições de DAS em repartição pública destinada à proposição de ações bastante específicas no contexto do agronegócio no caso analisado, há uma ampliação das exigências mínimas a serem preenchidas no que concerne à capacitação técnica do servidor.

Este seria o fato plausível para justificar a não modificação na qualificação dos servidores, uma vez que, conforme ressaltado por Pacheco (2002), a partir de 1995, com a reforma administrativa, houve uma alteração ascendente na escolaridade dos servidores federais. 
Por fim, a segunda inferência relaciona-se a uma possível não atualização da base de dados utilizada - o SIAPE -, notavelmente em relação a alterações no nível de formação dos servidores ao longo de suas carreiras.

Todavia é preciso salientar que a não modificação estatística indicada pelo teste relacionado ao nível de escolaridade dos burocratas ocupantes de cargos DAS no MAPA destoa da evolução percebida no nível geral da administração direta do governo central brasileiro. A esse respeito, em levantamento realizado pela Escola Nacional de Administração Pública (ENAP), publicado em 2018, verificou-se que houve, no período de 2000 a 2018, uma evolução de $26,38 \%$ no nível de escolaridade dos servidores da administração pública direta do governo federal brasileiro, identificando-se até mesmo que a taxa geral de servidores com doutorado representava, no último ano da análise, 1,43\% do total (ENAP, 2018). Esse percentual de servidores com doutorado está, portanto, acima do nível verificado no MAPA para os ocupantes de DAS Ademais, os próprios dados apresentados por Alessio (2017) apontam que política interna da Embrapa, empresa pública ligada ao ministério em questão, preconiza exigência mínima de nível de mestrado para ocupantes de cargos de direção, o que indica que, ao menos em determinados setores, há uma observância de maiores níveis instrucionais formais para a ocupação de cargos de direção.

Em relação à possibilidade de exercer atribuições de liderança, a premissa é de que servidores de carreira (efetivos) do governo federal, bem como aqueles ocupantes de cargos de confiança mais elevados na hierarquia de DAS tenderiam a possuir maior liberdade na definição de proposições. Na Tabela 3, são apresentados os principais indicadores relacionados aos servidores efetivos no âmbito do MAPA no período em análise.

\section{TABELA 3 TESTE DE MANN-WHITNEY U PARA A SITUAÇÃO DO VÍNCULO DE OCUPANTES DAS}

\begin{tabular}{|c|c|c|c|c|c|c|c|}
\hline \multirow[t]{2}{*}{ Situação do Vínculo } & \multirow{2}{*}{$\begin{array}{l}\text { Situação } \\
\text { Geral do } \\
\text { Vínculo }\end{array}$} & \multicolumn{2}{|c|}{1998} & \multicolumn{2}{|c|}{2018} & \multicolumn{2}{|c|}{$\begin{array}{c}\text { Teste Estatístico para } \\
\text { Amostras Independentes } \\
\text { Mann-Whitney U* }\end{array}$} \\
\hline & & Frequência & Percentual & Frequência & Percentual & Significância & Decisão \\
\hline Ativo Permanente & Efetivo & 262 & 46,5 & 108 & 25,7 & \multirow{8}{*}{, 000} & \multirow{8}{*}{$\begin{array}{c}\text { Rejeitar } \\
\text { a } \\
\text { hipótese } \\
\text { nula }\end{array}$} \\
\hline $\begin{array}{l}\text { Ativo Permanente Lei } \\
8.878 / 94\end{array}$ & Efetivo & 8 & 1,4 & - & - & & \\
\hline Exerc. Descent. Carreira* & Efetivo & - & - & 14 & 3,3 & & \\
\hline Exerc. $7^{0}$ art.93 8112 & Efetivo & - & - & 2 & 0,5 & & \\
\hline Req. de Outros Órgãos ** & Efetivo & 58 & 10,3 & 25 & 5,9 & & \\
\hline Requisitado ** & Efetivo & 39 & 6,9 & 13 & 3,1 & & \\
\hline Aposentado TCU733/94*** & Efetivo & 3 & 0,5 & 3 & 0,7 & & \\
\hline Aposentado*** & Efetivo & 6 & 1,1 & 28 & 6,7 & & \\
\hline
\end{tabular}




\begin{tabular}{|c|c|c|c|c|c|c|c|}
\hline \multirow[t]{2}{*}{ Situação do Vínculo } & \multirow[t]{2}{*}{$\begin{array}{l}\text { Situação } \\
\text { Geral do } \\
\text { Vínculo }\end{array}$} & \multicolumn{2}{|c|}{1998} & \multicolumn{2}{|c|}{2018} & \multicolumn{2}{|c|}{$\begin{array}{c}\text { Teste Estatístico para } \\
\text { Amostras Independentes } \\
\text { Mann-Whitney U* }\end{array}$} \\
\hline & & Frequência & Percentual & Frequência & Percentual & Significância & Decisão \\
\hline CLT ANS - Dec. Judicial & Contratado & 23 & 4,1 & - & - & & \\
\hline CLT ANS - Dec. 6657/08 & Contratado & - & - & 18 & 4,3 & & \\
\hline $\begin{array}{l}\text { CLT ANS Judicialmente } \\
\text { Cedido }\end{array}$ & Contratado & 2 & 0,4 & - & - & & \\
\hline Instituidor Pensão & Contratado & 1 & 0,2 & - & - & & \\
\hline Nomeado Cargo Comissão & Contratado & 161 & 28,6 & 210 & 49,9 & & \\
\hline Total & & 563 & 100,0 & 421 & 100,0 & & \\
\hline
\end{tabular}

$\left.{ }^{*}\right)$ Nível de significância: 0,05; Intervalo de Confiança: $95 \%$.

${ }^{* *}$ Exercício Descentralizado de Carreira: "[...] destinado aos servidores ativos de determinadas carreiras, que em sua legislação específica prevê que seus integrantes poderão ter exercício em outros órgãos, mantida a lotação no órgão de origem [...]” (Ministério do Planejamento, Desenvolvimento e Gestão, 2018, p. 50).

(**) Requisitados de Outros Órgãos: “[...] o agente público, sem suspensão ou interrupção do vínculo funcional com a origem, passa a ter exercício fora da unidade de lotação[...]” (Ministério do Planejamento, Desenvolvimento e Gestão, 2018, p. 61).

${ }^{* * *}$ Equiparados a efetivos de acordo com o Decreto n 5.497, de 21 de julho de 2005 (2005).

Fonte: Dados da pesquisa.

Conforme se verifica na Tabela 3, o teste indica a rejeição da hipótese nula, o que demonstra que, estatisticamente, o nível de servidores efetivos, ocupantes de posições de DAS, apresenta diferença na comparação entre os anos de 1998 e 2018. Essas diferenças são notadas expressivamente na diminuição do percentual de servidores em posições de ativos permanentes, bem como na ampliação do número de burocratas nomeados em cargos de comissão.

Destaca-se que a situação de vínculo de ativo permanente significa que o servidor prestou concurso público especificamente para compor carreira no MAPA. Já os cargos de comissão são ocupados por servidores externos à carreira pública, incorporados mediante confiança do presidente, ministro ou seu superior imediato, e podem ser desligados a qualquer tempo, uma vez que não possuem estabilidade.

Considerando a premissa de D’Araujo (2009), diante de uma possível falta de transparência nos critérios de seleção nos cargos de confiança e do crescimento de indicações políticas advindas com os governos de coalizão, os dados reportados na Tabela 3 podem levar a um cenário em que burocratas passam a ter menor liberdade na tomada de decisão ${ }^{22}$ e expertise reduzida em relação aos temas vinculados ao MAPA. É preciso salientar que, a despeito do fato de o Decreto no 9.021 , de 31 de março de 2017 (2017) - que versa sobre o percentual mínimo de burocratas em cada um dos estratos DAS - delimitar percentuais mínimos de servidores efetivos em posições DAS, essa observância se dá de forma agregada, ou seja, em todo o conjunto de cargos do governo federal. Adicionalmente, conforme se percebe na Tabela 3, a cota de efetivos pode englobar servidores requisitados de outras repartições governamentais.

\footnotetext{
${ }^{22}$ Preconiza-se que servidores estáveis de carreira, mesmo ocupantes de posições de confiança, teriam maior liberdade em exercer papéis de liderança e tomada de decisão.
} 
Além disso, considerando as atribuições dos níveis de DAS, elencadas no Quadro 2, é possível perceber que servidores de direção de níveis mais elevados (101.4, 101.5 e 101.6) teriam condições de exercer funções de liderança. A condição de liderança é entendida em relação ao grau de liberdade de proposição de programas e/ou políticas governamentais convertido em orientações dos atores políticos aos demais servidores públicos; bem como em negociação e sugestão de ajustes naquelas ações existentes aos agentes políticos (Pires, 2012). Esses fatos já foram percebidos como atinentes ao contexto do MAPA, conforme se verifica em Igari e Pivello (2011), que apontam que o então Ministro Hugo Leme, no ano de 1965, denominou "Comissão de alto nível" servidores ocupantes de posições de direção e assessoramento superior do Departamento de Recursos Naturais Renováveis, para a criação de um anteprojeto do Código Florestal. A Tabela 4 apresenta uma comparação estatística no número de ocupantes dessas posições mais elevadas, tendo por base a situação de efetivos e de contratados.

\section{TABELA 4 TESTE DE MANN-WHITNEY U PARA BUROCRATAS EM CONDIÇÕES DE EXERCER LIDERANÇA}

\begin{tabular}{|c|c|c|c|c|c|c|c|}
\hline \multirow[t]{2}{*}{ SITUAÇÃO } & \multirow[t]{2}{*}{ Subfunção } & \multirow[b]{2}{*}{ Frequência } & \multirow[b]{2}{*}{ Frequência } & \multirow[t]{2}{*}{ Significância } & \multirow[t]{2}{*}{ Decisão } & \multicolumn{2}{|c|}{$\begin{array}{c}\text { Teste Estatístico para } \\
\text { Amostras Independentes } \\
\text { Mann-Whitney U }\end{array}$} \\
\hline & & & & & & Signif. & Decisão \\
\hline \multirow{5}{*}{$\begin{array}{l}\text { Efetivos/ De } \\
\text { carreira ** }\end{array}$} & DAS 101.4 & $21\left(3^{\star \star}\right)$ & $50\left(29^{\star \star}\right)$ & & \multirow{5}{*}{$\begin{array}{l}\text { Reter a } \\
\text { hipótese } \\
\text { nula* }\end{array}$} & \multirow{12}{*}{,653 } & \multirow{12}{*}{$\begin{array}{c}\text { Reter a } \\
\text { hipótese } \\
\text { nula* }^{*}\end{array}$} \\
\hline & DAS 101.5 & $10\left(2^{\star \star}\right)$ & $18\left(8^{\star \star}\right)$ & & & & \\
\hline & DAS 101.6 & $3\left(1^{* \star}\right)$ & $2\left(1^{\star \star}\right)$ & ,337 & & & \\
\hline & Secretário Executivo & - & 1 & & & & \\
\hline & Subtotal & 33 & 63 & & & & \\
\hline \multirow{5}{*}{ Contratados } & DAS 101.4 & 12 & 32 & & \multirow{5}{*}{$\begin{array}{l}\text { Reter a } \\
\text { hipótese } \\
\text { nula* }\end{array}$} & & \\
\hline & DAS 101.5 & 5 & 10 & & & & \\
\hline & DAS 101.6 & - & 2 & ,625 & & & \\
\hline & Secretário Executivo & 1 & - & & & & \\
\hline & Subtotal & 18 & 44 & & & & \\
\hline \multicolumn{2}{|c|}{ Total nas Subfunções analisadas } & 52 & 115 & & & & \\
\hline \multicolumn{2}{|c|}{ TOTAL DE SERVIDORES DAS } & 563 & 421 & & & & \\
\hline
\end{tabular}

Nível de significância: 0,05; Intervalo de Confiança: $95 \%$.

${ }^{*}$ ) O teste foi realizando comparando o número de servidores apenas nas quatro subfunções (estratos) nos anos de 1998 e 2018. É preciso, portanto, deixar claro que não são considerados burocratas em outras posições neste teste.

$\left.{ }^{* *}\right)$ Estrato de servidores efetivos relaciona o número de servidores em situação funcional de ativos permanentes.

Fonte: Dados da pesquisa. 
Os resultados externados na Tabela 4 indicam que não houve mudanças significativas nas médias de servidores passíveis de exercerem liderança, considerando-se o aspecto da capacidade individual da proposição de políticas públicas e programas governamentais. Essa não distinção estatística ocorre na comparação dos estratos de servidores efetivos entre si, nos contratados entre si, e, por fim, na contraposição de efetivos e contratados no período confrontado.

Fato passível de ser verificado é que o número de servidores efetivos, nos estratos analisados em questão, é superior ou, quando não, é igual ao número de contratados. Entretanto, quando se analisa o número de burocratas de carreira do próprio MAPA, que são aqueles que realizaram concursos públicos especificamente para o órgão em questão, verifica-se que houve um crescimento ${ }^{23}$ relevante na participação desse segmento apenas no estrato DAS 101.4. Esse fato pode ser concebido como positivo, uma vez que esses servidores, na referida subfunção, na categoria de ativos permanentes, ocupavam majoritariamente a função de coordenador geral ou superintendente ${ }^{24}$. Nas superintendências, conforme indicado por Lopez e Praça (2015), estão as posições mais visadas para indicações políticas em disputas de bancadas parlamentares.

\section{CONCLUSÕES}

O presente trabalho teve por pretensão analisar a capacidade individual da burocracia no contexto do MAPA em relação à proposição de políticas públicas no âmbito do agronegócio brasileiro. Essa análise foi possível mediante seleção de proxies representativas de três capacidades individuais: experiência e conhecimento político; processamento de informações; e liberdade em relação a funções gerenciais, entendida também como capacidade de liderança.

Em relação ao conhecimento político e à experiência dos burocratas, verificou-se uma tendência de estabilidade entre os servidores ocupantes de posições DAS nos períodos de 2006 a 2009 e de 2010 a 2012. Outrossim, oscilações mais bruscas ocorreram em mudanças de titulares, em reorganizações estruturais por meio de reformas administrativas internas ou instadas mediante decretos presidenciais, que geralmente ocorrem visando aprimorar os níveis de eficiência na estrutura governamental.

No que concerne à capacidade de processar informações, a análise dos níveis de educação formal dos servidores DAS indicou a não ocorrência de modificações estatisticamente relevantes. Muito embora os níveis se estabeleçam acima de 70\% em ambos os anos para ensino superior, as informações disponíveis não indicaram evolução em capacitações mais avançadas, como especialização e doutorado especialmente.

A considerar a evolução nacional no número de diplomados em nível de pós-graduação no período ${ }^{25}$, bem como aquela indicada em $\operatorname{ENAP}$ (2018), percebe-se que, no contexto intraorganizacional do MAPA, esse processo não foi o mesmo. Esse fato requer certa atenção dos tomadores de decisão, uma vez que a capacidade de aplicação de conhecimentos técnicos e técnicas analíticas é central à proposição de intervenções mais rápidas e eficientes, conforme salientam Wu et al. (2015).

Por fim, os resultados indicam modificações estatisticamente relevantes no perfil dos servidores em relação à situação de vinculação ao MAPA. Há, por um lado, redução no número de servidores em

\footnotetext{
23 Tomando como 2018 o aspecto posterior de comparação em relação aos indicativos do ano de 1998.

${ }^{24}$ Dos 29 servidores no ano de 2018, apenas três ocupavam a função de chefe de gabinete, com exceção para os cargos de superintende (14 servidores) e coordenador geral (12 servidores). Em 1998 todos os três servidores ocupavam a posição de coordenação geral.

${ }^{25}$ Conforme apresentado no trabalho de Magalhães e Real (2018), com a análise de dados da Coordenação de Aperfeiçoamento de Pessoal de Nível Superior (CAPES), em 2016 havia cerca de 260 mil pesquisadores vinculados a cursos de pós-graduação stricto senso no Brasil, ao passo que em 1998 esse quantitativo era da ordem de mais de 76 mil.
} 
posições de contratação por concurso, especificamente para cargos no ministério, e, por outro, uma ampliação de ocupantes nomeados em cargos de comissão. Todavia, em estratos mais elevados DAS 101.4, 101.5 e 101.6 - não há alteração na composição de ocupantes relacionados à condição de contratados e efetivos (servidores concursados).

Dessa forma, levando-se em conta o construto definido no presente trabalho, não houve nos anos comparados modificações na capacidade de liderança ou alterações substantivas no nível de liberdade das funções gerenciais, mesmo existindo modificações institucionais no período, como a maior participação de servidores de carreira nesses cargos.

O conjunto de fatos, especialmente quanto aos construtos relacionados à capacidade de processamento de informações, bem como aos níveis de exercício de liderança, evidencia certo conservadorismo da capacidade da burocracia do MAPA. Seria esperada uma ampliação na capacidade de processo de informações e de uma maior propensão à ampliação da participação de servidores ativos no exercício de cargos de liderança quando se comparam informações em um horizonte temporal de vinte anos. Isso é esperado, considerando, principalmente, as modificações sofridas pelo agronegócio nesse mesmo período com a ampliação dos níveis de produtividade, bem como o crescente protagonismo do Brasil nesse setor no comércio internacional ${ }^{26} \mathrm{e}$ as alterações institucionaislegais, como a maior participação de servidores concursados em cargos superiores. É interessante, nesse sentido, repensar as formas de reposição de servidores em situações de ativos permanentes, bem como a delimitação da obrigatoriedade dos percentuais mínimos relacionados no Decreto no 9.021, de 31 de março de 2017 (2017), para cada um dos órgãos que compõem o governo federal, ou seja, de maneira dissociada.

Os resultados do presente trabalho trazem contribuições associadas à relevância da consideração da capacidade individual do staff profissional, focando burocratas no âmbito do setor governamental voltado ao agronegócio nacional brasileiro. Além disso, o construto aqui apresentado pode suprir uma carência apontada por Wu et al. (2015), qual seja: elencar instrumentos que possam mensurar a capacidade individual da burocracia dentro do escopo maior das discussões relacionadas à capacidade governamental de entrega de soluções eficazes à sociedade. Valendo-se das análises aqui apresentadas, os atores políticos terão condições, igualmente, de elencar quais capacidades individuais da burocracia do agronegócio nacional poderão ser fortalecidas, o que contribui para o refinamento de estratégias de aprimoramento das ações governamentais a serem implementadas no setor agrícola brasileiro. Assim, contornam-se, parcialmente, as lacunas encontradas em Olsen (2006) e Pires (2012), que reportam a carência de estudos com foco na capacidade de assertividade das ações governamentais delimitadas ao setor rural do Brasil.

Mesmo apresentando essas contribuições, algumas limitações do presente trabalho precisam ser apontadas. Por se tratar de uma análise com dados em seção cruzada, especificamente nos construtos que fizeram uso do teste estatístico - mesmo sendo utilizados com recorrência a pesquisas similares a esta -, deve-se reconhecer a deficiência de não serem identificadas modificações na série temporal dos anos compreendidos no período analisado.

Somando-se a essa questão, determinados pontos de interesse delimitados para a análise das

${ }^{26}$ Conforme aponta Bojanic (2017). 
RAP | Capacidades individuais da burocracia pública do agronegócio brasileiro

capacidades individuais dos servidores poderiam ser mais bem explicados se houvesse a utilização de metodologias qualitativas, como a realização de entrevistas, por exemplo. Finalmente, possíveis vieses nos dados utilizados, como a falta de atualização destes, com destaque para os relacionados aos níveis de formação educacional dos servidores, bem como a não discriminação da área de formação instrucional dos servidores, podem prejudicar a exatidão dos resultados obtidos.

Os resultados deste estudo abrem novas possibilidades a pesquisas futuras. Por exemplo, uma análise de dados em painel que possa identificar modificações estruturais da burocracia em uma comparação anual e verificação da percepção dos burocratas mediante a coleta de dados primários com vistas a identificar fatores intervenientes na capacidade individual desses atores em relação ao enfoque da eficácia na proposição de políticas públicas e programas governamentais. 


\section{REFERÊNCIAS}

Abbey, L. A., Baer, W., \& Filizzola, M. (2006). Growth, efficiency, and equity: the impact of agribusiness and land reform in Brazil. Latin American Business Review, 7(2), 93-115.

Abrúcio, F. L., \& Loureiro, M. R. (2018). Burocracia e ordem democrática: desafios contemporâneos e experiência brasileira. In R. Pires, G. Lotta, \& V. E. Oliveira (Orgs.), Burocracia e políticas públicas no Brasil: interseções analíticas (Cap. 1., pp. 23-57). Rio de Janeiro, RJ: Ipea, Enap.

Alessio, M. F. (2017). Estratégias de escolha de dirigentes públicos no Brasil: alcances e limitações das experiências recentes à luz do debate internacional (Tese de Doutorado). Fundação Getulio Vargas, São Paulo, SP.

Bacha, C. J. C. (2004). Economia e política agrícola no Brasil. São Paulo, SP: Atlas.

Baekgaard, M., Mortensen, P. B., \& Seeberg, H. B. (2018). The bureaucracy and the policy agenda. Journal of Public Administration Research and Theory, 28(2), 239-253.

Bogoni, N. M., Nelson, H., \& Beuren, I. M. (2011). Análise da relação entre crescimento econômico e gastos públicos nas maiores cidades da região Sul do Brasil. Revista de Administração Pública, 45(1), 159-179.

Bojanic, H. A. (2017). The rapid agricultural development of Brazil in the last 20 years. EuroChoices, 16(1), 5-10.

Bresser-Pereira, L. C. (1996). Da administração pública burocrática à gerencial. Revista do Serviço Público, 47(120), 7-40.

Bresser-Pereira, L. C. (1998). A reforma do estado dos anos 90: lógica e mecanismos de controle. Lua Nova: Revista de Cultura e Política, 45, 49-95.

Castro, J. A., \& Ribeiro, J. A. (2009). As políticas sociais e a Constituição de 1988: conquistas e desafios. In Instituto de Pesquisa Econômica Aplicada (Org.), Políticas sociais: acompanhamento e análise - vinte anos da Constituição federal (2a ed., Cap. 1, pp. 17-96). Brasília, DF: Autor.

Castro, N. R., Barros, G. S. A. D. C., Almeida, A. N., Gilio, L., \& Morais, A. C. D. P. (2020). The Brazilian agribusiness labor market: measurement, characterization and analysis of income differentials. Revista de Economia e Sociologia Rural, 58(1), 1-20.

Cavalcante, P., \& Lotta, G. (2015). Burocracia de Médio Escalão: perfil, trajetória e atuação. Brasília, DF: ENAP.

Cavalcante, P., Magalhães, A., Goellner, I., \& Palotti, P. (2018). Perfil de comando do núcleo de governo no Brasil. In P. Cavalcante, \& G. Lotta (Orgs.), O Presidente e seu núcleo de governo: a coordenação do Poder Executivo (Cap. 3, pp. 89-112). Brasília, DF: Ipea.

Constituição da República Federativa do Brasil de 1988. (1988). Brasília, DF. Recuperado de http://www.planalto.gov.br/ccivil_03/constituicao/ constituicao.htm

Costa, V. M. (1993). Sistemas de governo e administração público no Brasil. In J. Andrade, \& L. Jaccoud. (Orgs.), Estrutura e organização do Poder Executivo: administração pública brasileira (pp. 203270). Brasília, DF: ENAP/CEDEC.

D’Araújo M. C. (2009). A elite dirigente do governo Lula. Rio de Janeiro, RJ: FGV CPDOC.

Decreto $n^{\circ} 5.351$ de 21 de janeiro de 2005. (2005). Aprova a Estrutura Regimental e o Quadro Demonstrativo dos Cargos em Comissão e das Funções Gratificadas do Ministério da Agricultura, Pecuária e Abastecimento, e dá outras providências. Diário Oficial da União. Brasília, DF: Presidência da República.

Decreto $n^{\circ}$ 5.497, de 21 de julho de 2005. (2005). Dispõe sobre o provimento de cargos em comissão do Grupo-Direção e Assessoramento Superiores - DAS, níveis 1 a 4, por servidores de carreira, no âmbito da administração pública federal. Diário Oficial da União. Brasília, DF: Presidência da República.

Decreto $n^{\circ} 6.348$ de 8 de janeiro de 2008. (2008). Altera os Anexos I e II ao Decreto no 5.351, de 21 de janeiro de 2005, que aprova a Estrutura Regimental e o Quadro Demonstrativo dos Cargos em Comissão e das Funções Gratificadas do Ministério da Agricultura, Pecuária e Abastecimento, e o art. $2^{\circ}$ do Decreto $n^{\circ} 5.741$, de 30 de março de 2006, que regulamenta os arts. 27-A, 28-A e 29-A da Lei $\mathrm{n}^{\circ} 8.171$, de 17 de janeiro de 1991, que organiza o Sistema Unificado de Atenção à Sanidade 
Agropecuária. Diário Oficial da União. Brasília, DF: Presidência da República.

Decreto $n^{\circ} 6.657$ de 20 de novembro de 2008. (2008). Regulamenta o art. 310 da Medida Provisória no 441, de 29 de agosto de 2008, dispondo sobre a remuneração dos empregados anistiados pela Lei no 8.878, de 11 de maio de 1994, que retornarem ao serviço na administração pública federal direta, autárquica e fundacional. Diário Oficial da União. Brasília, DF: Presidência da República.

Decreto $n^{\circ} 7.127$ de 4 de março de 2010. (2010). Aprova a Estrutura Regimental e o Quadro Demonstrativo dos Cargos em Comissão e das Funções Gratificadas do Ministério da Agricultura, Pecuária e Abastecimento, e dá outras providências. Diário Oficial da União. Brasília, DF: Presidência da República.

Decreto $n^{\circ}$ 8.852, de 20 de setembro de 2016 . (2016). Aprova a Estrutura Regimental e o Quadro Demonstrativo dos Cargos em Comissão e das Funções de Confiança do Ministério da Agricultura, Pecuária e Abastecimento, remaneja cargos em comissão e funções gratificadas e substitui cargos em comissão do Grupo Direção e Assessoramento Superiores - DAS por Funções Comissionadas do Poder Executivo - FCPE. Brasília, DF. Recuperado de http://www.planalto.gov.br/ccivil_03/_ato20152018/2016/decreto/D8852.htm\#art9

Decreto $n^{\circ}$ 9.021, de 31 de março de 2017. (2017). Altera o Decreto no 5.497, de 21 de julho de 2005, que dispõe sobre o provimento de cargos em comissão do Grupo-Direção e Assessoramento Superiores - DAS, níveis 1 a 4, por servidores de carreira, no âmbito da administração pública federal. Brasília, DF. Recuperado de http://www.planalto.gov.br/ ccivil_03/_ato2015-2018/2017/decreto/D9021.htm

Escola Nacional de Administração Pública. (2018). Informe de Pessoal - Análise por Organização. Recuperado de https://repositorio.enap.gov.br/ handle/1/3604

Field, A. (2009). Descobrindo a Estatística Usando o SPSS. Porto Alegre, RS: Artmed.

Filippi, A. C. G., Guarnieri, P., Carvalho, J. M., Reis, S. A., \& Cunha, C. A. (2019). New configurations in Brazilian agribusiness: rural warehouse condominiums. Journal of Agribusiness in Developing and Emerging Economies, 10(1), 41-63.
Fischer, F., Miller, G. J, \& Sidnei, M. R. (2017). Handbook of public policy analysis: theory, politics, and methods. Boca Raton, FL: Routledge.

Freire, A. O., Knop, M. N. H., Alves, P. A., Cavalcante, P. L. C., \& Palotti, P. L. M. (2017). Burocracia federal da área de infraestrutura: perfil, atuação, trajetória e percepções. In J. M. P. Paula, P. L. M. Palotti, \& P. L. C. Cavalcante (Orgs.), Burocracia Federal de Infraestrutura Econômica: reflexões sobre capacidades estatais (Cap.1, pp. 23-60). Brasília, DF: Enap, Ipea.

Gonçalves, C. A., Jr., Alves, Y. B., Shikida, P. F. A., Staduto, J. A. R., \& Rocha, W. F. D., Jr. (2009). Um estudo das deliberações da Câmara Setorial do Açúcar e do Álcool, usando análise de correspondência. Revista de Economia e Sociologia Rural, 47(1), 183-210.

Gow, J. I. (2012). Réforme administrative. In L. Côté, \& J.-F. Savard (Dir.), Le Dictionnaire encyclopédique de l'administration publique [en ligne]. Recuperado de www.dictionnaire.enap.ca

Igari, A. T., \& Pivello, V. R. (2011). Crédito rural e código florestal: irmãos como Caim e Abel? Ambiente \& Sociedade, 14(1), 133-150.

Kraft, M. E., \& Furlong, S. R. (2007). Public Policy: politics, analisys, and alternatives. Washington, DC: CQ Press.

Lavee, E., Cohen, N., \& Nouman, H. (2018). Reinforcing public responsibility? Influences and practices in street-level bureaucrats' engagement in policy design. Public Administration, 96(2), 333-348.

Lei no 8.878 de 11 de maio de 1994. (1994). Dispõe sobre a concessão de anistia nas condições que menciona. Diário Oficial da União. Brasília, DF: Presidência da República.

Lei $n^{\circ} 10.683$ de 28 de maio de 2003. (2003). Dispõe sobre a organização da Presidência da República e dos Ministérios, e dá outras providências. Diário Oficial da União. Brasília, DF: Presidência da República.

Lipsky, M. (2019). Burocracia no nível da rua: os dilemas do indivíduo nos serviços públicos. Brasília, DF: ENAP.

Lopes, I. V., \& Lopes, M. D. R. (2010). O fim das cinco décadas de tributação da agricultura no Brasil. Revista de Política Agrícola, 19(spe.), 31-41. 
Lopez, F. G. (2017). Cargos de confiança nos mandatos Lula e Dilma. In Instituto de Pesquisa Econômica Aplicada (Org.), Boletim de Análise Político-Institucional (n. 12, pp. 29-36). Brasília, DF: Autor.

Lopez, F. G., Bugarin, M., \& Bugarin, K. (2014). Rotatividade nos cargos de confiança da administração federal brasileira (1999-2013). Revista do Serviço Público, 65(4), 439-461.

Lopez, F. G., \& Praça, S. (2015). Critérios e lógicas de nomeação para o alto escalão da burocracia federal brasileira. In F. G. Lopez. (Org.), Cargos de confiança no presidencialismo de coalizão brasileiro (Cap. 3, pp. 107-130). Brasília, DF: Ipea.

Machado, A. P. C. (2009). A formulação da Política Comercial Externa Agrícola: condicionantes internacionais e domésticos da transformação institucional do Ministério da Agricultura, Pecuária e Abastecimento (Dissertação de Mestrado). Universidade de Brasília, Brasília, DF.

Magalhães, A. S., \& Real, G. C. M. (2018). Situando os debates sobre a avaliação da pós-graduação: os estudos do campo pelo campo. Eccos, 46, 131-148.

Medeiros, E. A. D., Araújo, M., Belloni, M. F., Leonard, R. B. A., Bastos, E. T., Santos, L. M. ... Contini, E. (2005). Prioridades estratégicas do Mapa 2005-2006. Revista de Política Agrícola, 14(3), 5-13.

Ministério do Planejamento, Desenvolvimento e Gestão. (2018). Pessoas. Manual: Movimentação de Pessoal. Brasília, DF: Autor.

Moreira, V. R., Kureski, R., \& Pereira-Veiga, C. (2016). Assessment of the economic structure of Brazilian agribusiness. The Scientific World Journal, 7517806, 1-10. Recuperado de https://doi. org/10.1155/2016/7517806

Mukherjee, I., \& Bali, A. S. (2019). Policy effectiveness and capacity: two sides of the design coin. Policy Design and Practice, 2(2), 103-114.

Nigro, F. A., \& Nigro, L. G. (1970). Modern public administration. New York, NY: Harper \& Row.

Olsen, J. P. (2006). Maybe It Is Time to Rediscover Bureaucracy. Journal of Public Administration Research and Theory, 16(1), 1-24.

Pacheco, R. S. (2002). Política de recursos humanos para a reforma gerencial: realizações do período 1995-2002. Revista do Serviço Público, 53(4), 79-106.
Paula, A. P. P. D. (2005). Por uma nova gestão pública. Rio de Janeiro, RJ: FGV.

Paula, J. M. P., Palotti, P. L. M., Cavalcante, P. L.C., \& Alves, P. A. (2017). Burocracia Federal de Infraestrutura Econômica: reflexões sobre capacidades estatais. Brasília, DF: Enap, Ipea.

Pires, R., Lotta, G., \& Oliveira, V. E. (2018). Burocracia e políticas públicas no Brasil: interseções analíticas. Brasília, DF: Ipea.

Pires, R. R. C. (2012). Burocracias, gerentes e suas "histórias de implementação": narrativas do sucesso e fraco de programas federais. In C. A. P. Faria (Org.), Implementação de Políticas Públicas - Teoria e prática. Belo Horizonte, MG: PUC Minas.

Praça, S., Freitas, A., \& Hoepers, B. (2012). A rotatividade dos servidores de confiança no governo federal brasileiro, 2010-2011. Novos estudos CEBRAP, (94), 91-107.

Rezende, R. (2017, abril). Provimento de cargos em comissão por servidores sem vínculo efetivo: o que muda com o Decreto no 9.021/2017? (Boletim Legislativo, n. 61). Brasília, DF: Núcleo de Estudos e Pesquisas, Senado Federal.

Romero, C. (2011). Pemedebista foi acusado de lotear Conab. Recuperado de https://www2.senado.leg.br/ bdsf/bitstream/handle/id/466407/complemento_1. $\mathrm{htm}$ ? sequence $=2$ \&isAllowed $=\mathrm{y}$

Simão, G. L., Freitas, A. F., Silva, E. A., NardiBastos, B. R., Salgado, R. J. D. S. F., \& Amodeo, N. B. P. (2017). Políticas Públicas de desenvolvimento local e adensamento de capital social: análise do Programa de aquisição de alimentos (PAA) em quatro municípios de Minas Gerais. Revista de Administração da Universidade Federal de Santa Maria, 10(2), 288-306.

Souza, C. (2001). Federalismo e descentralização na Constituição de 1988: processo decisório, conflitos e alianças. Dados, 44(3), 513-560.

Souza, C. (2014). Federalismo e Capacidades estatais: o papel do Estado-Membro na Política de Assistência Social. In A. A. Gomide, \& R. R. Pires (Orgs.), Capacidades estatais e democracia: arranjos institucionais de políticas públicas (pp. 269-297). Brasília, DF: Ipea. 
Souza, C. (2017). Modernização do Estado e construção de capacidade burocrática para a implementação de políticas federalizadas. Revista de Administração Pública, 51(1), 27-45.

Steingerg, M. (2014). Strategic design and the art of public sector innovation. In C. Bason (Ed.), Design for policy: design for social responsibility (Cap. 6). Aldershot, UK: Gower Publisher.

Vicari, L. M. (2020). Capacidades estatais e policy networks: um estudo das relações entre o Ministério da Agricultura (MAPA) e o empresariado do agronegócio (Dissertação de Mestrado). Fundação João Pinheiro, Belo Horizonte, MG.

Vries, H. D., Bekkers, V., \& Tummers, L. (2016). Innovation in the public sector: A systematic review and future research agenda. Public administration, 94(1), 146-166.

Workman, S. (2015). The dynamics of bureaucracy in the US Government. Cambridge, MT: Cambridge University Press.

Wu, X., Howlett, M., \& Ramesh; M. (2018). Policy Capacity: conceptual framework and essential componentes. In X. Wu, M. Howlett, \& M. Ramesh (Orgs.), Policy Capacity and Governance: assessing governamental competences and capabilities in theory and practice. Cham, UK: Palgrave Macmillan.

Wu, X., Ramesh, M., \& Howlett, M. (2015). Policy capacity: A conceptual framework for understanding policy competences and capabilities. Policy and Society, 34(3-4), 165-171.

\section{Gustavo Leonardo Simão}

iD

https://orcid.org/0000-0002-5989-100X

Pós-doutor em Administração pela Universidade Federal de Viçosa (UFV); Doutor em Administração pela Universidade Federal de Lavras (UFLA); Professor Adjunto do Departamento de Administração na Universidade Federal do Espírito Santo (UFES). E-mail: gustavo.simao@ufes.br

\section{Suely de Fátima Ramos Silveira}

https://orcid.org/0000-0002-1303-7190

Doutora em Economia pela Universidade de São Paulo (USP); Professora Associada IV do Departamento de Administração e Contabilidade na Universidade Federal de Viçosa (UFV). E-mail: sramos@ufv.br 